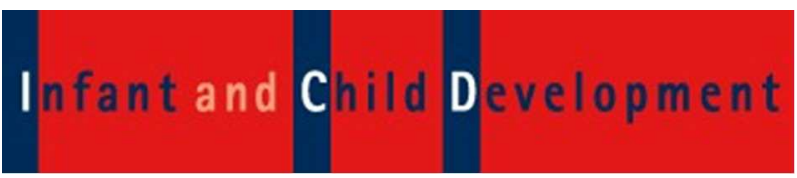

\title{
Children's trust in print: What is the impact of late exposure to reading instruction?
}

\begin{tabular}{|r|l|}
\hline Journal: & Infant and Child Development \\
\hline Manuscript ID & ICD-17-0119.R2 \\
\hline Keywords: & Testimony, selective trust, print, literacy \\
\hline Abstract: & $\begin{array}{l}\text { Prior research in England has indicated that, unlike pre-readers, young } \\
\text { children who have learned to decode simple words view print-based } \\
\text { information as a more authoritative source of knowledge than purely oral } \\
\text { information. We predicted that children in Norway - who start to receive } \\
\text { formal reading instruction at a relatively late age - would be slower to } \\
\text { display this bias toward print-based information. Accordingly, we tested 4- } \\
\text { 6 year-olds (N = 96) in Norway. As expected, these children showed a } \\
\text { delayed emergence of the bias toward print over speech. Unexpectedly, } \\
\text { however, children who had successfully gained a basic reading ability prior } \\
\text { to any exposure to formal reading instruction in school were no more } \\
\text { trusting of print than their pre-reading peers. These results suggest that } \\
\text { the ability to decode simple words is an important condition for selective } \\
\text { trust in print-based information but that exposure to formal reading } \\
\text { instruction in school may also be necessary. }\end{array}$ \\
\hline \multicolumn{2}{|l}{} \\
\hline
\end{tabular}


Children's trust in print:

What is the impact of late exposure to reading instruction?

Keywords: Testimony; selective trust; print; literacy 
TRUST IN PRINT 2

\begin{abstract}
Prior research in England has indicated that, unlike pre-readers, young children who have learned to decode simple words view print-based information as a more authoritative source of knowledge than purely oral information. We predicted that children in Norway - who start to receive formal reading instruction at a relatively late age - would be slower to display this bias toward print-based information. Accordingly, we tested 4-6 year-olds $(N=96)$ in Norway. As expected, these children showed a delayed emergence of the bias toward print over speech. Unexpectedly, however, children who had successfully gained a basic reading ability prior to any exposure to formal reading instruction in school were no more trusting of print than their pre-reading peers. These results suggest that the ability to decode simple words is an important condition for selective trust in print-based information but that exposure to formal reading instruction in school may also be necessary.
\end{abstract}




\section{Children's trust in print:}

\section{What is the impact of late exposure to reading instruction?}

Young children gain knowledge about the world from what other people tell them

(Harris, 2012; Koenig \& Harris, 2005). With age, however, they are increasingly exposed to an additional medium of information - the written word. This exposure occurs indirectly at first, when being read to or through observing other people reading and being guided by print, and then directly as children acquire the skills to crack the written code themselves. Both oral and written forms of testimony provide wide-ranging opportunities for learning but they also carry the risk of conveying misleading information (e.g., mistakes, lies, distortions or out-of-date facts). Children's epistemic vigilance and selective trust in oral sources has been the focus of intensive research in recent years (for reviews see Harris, Koenig, Corriveau \& Jaswal, 2018; Mills, 2013; Robinson \& Einav, 2014). Comparatively little, however, is known about young children's trust in print. Yet, understanding children's assumptions about print reliability is particularly pressing given the ever-increasing amounts of unchecked written information that they may access online.

A small number of studies has recently begun to compare children's relative trust in oral versus print-based information. Do children treat text as a particularly authoritative medium? Converging evidence suggests that the answer to this question depends on children's ability to decode words for themselves. Unlike pre-readers, children who can engage in simple decoding are more likely to trust information read aloud from print than information that is purely oral. In a study by Robinson, Einav and Fox (2013), two dolls provided children with conflicting information about which of several pictures illustrated an unfamiliar target: one doll read aloud from printed labels (e.g., "This word says neri”) that were illegible to the child whereas the other doll made standalone oral statements (e.g., "This is the neri"). Early readers (aged 4-6 years) more frequently endorsed the doll who made 


\section{TRUST IN PRINT 4}

print-based suggestions whereas pre-readers (aged 3-4 years) were equally likely to trust either doll (see also Einav, Robinson, \& Fox, 2013). Further analysis showed that basic word decoding (as indexed by a very simple word-picture matching task) rather than the extent of reading ability was a key predictor of trust in print. That is, performance on the Early Word Recognition Test (Hatcher, Hulme, \& Ellis, 1994), which tests reading beyond basic word decoding, did not confer any additional predictive power.

A comparable developmental shift between pre- and early readers was found when children could choose between oral versus print-based instructions to guide their actions on an apparatus (Corriveau, Einav, Robinson, \& Harris, 2014). Furthermore, early readers' trust in print has been compellingly demonstrated by their acceptance of implausible, printed information that conflicts with their expectations and which they reject when conveyed orally. In contrast, pre-readers reject the implausible information to the same extent in both conditions (Eyden, Robinson, \& Einav, 2014; Eyden, Robinson, Einav, \& Jaswal, 2013).

In summary, the evidence consistently indicates that once young children have a basic ability to decode the written word they rapidly regard it as a particularly authoritative source of information about the world. Observation of adults' reliance on print is not sufficient for this bias to emerge: Pre-readers, despite having extensive experience of observing others use print for gaining information, do not regard it as more authoritative than oral testimony. Arguably, for them the printed word that is read aloud is interpreted no differently from a spoken word.

What underlies the emergence of this bias toward print-based information? Although previous research reveals a relationship between basic decoding ability and trust in print, it remains an open question whether decoding ability is the key causal factor. The effect of decoding ability was shown to hold after age was controlled statistically in most of the above studies but it is plausible that decoding ability is an index of other underlying cognitive or 
TRUST IN PRINT 5

linguistic skills that increase between 3 and 5 years. Corriveau et al. (2014) showed that the size of children's vocabulary was not associated with their preferential trust in print, but there may be other factors. In addition, as Robinson et al. (2013) point out, it is difficult to determine whether the acquisition of basic word decoding skill is a sufficient condition for trust in print or whether being exposed to formal reading instruction at school also plays a key role in how children consider print-based information. It seems plausible that the process of learning to read makes children more aware of print as a source of knowledge that can be differentiated from spoken testimony. What teachers say and do when they teach children to read may be important in lending print its authority. For example, instructional reading texts often present pictures and words side by side, thereby reinforcing the impression that written texts offer a veridical source of information. Most of the above studies were carried out in the UK where learning to read and school-based reading instruction are almost invariably confounded given that children primarily begin to decode words as a result of instruction at school. Corriveau et al. (2014) conducted their study in the USA but children's school experience was not systematically noted because a large proportion of participants were recruited from a local science museum.

The aim of the current study was to gain further insight into the developmental route underlying trust in print by replicating Robinson et al.'s (2013) study with a Norwegian sample. Norway offers an especially useful point of comparison for two reasons: First, there is a considerable difference in the timing of the literacy curriculum in the UK and Norway. Specifically, the age at which children typically receive formal reading instruction is later in Norway. In the UK, children start attending school at 4-5 years of age (Reception class) when literacy instruction starts formally in accordance with the national statutory guidance (Early Years Foundation Stage Framework, Department for Education, 2012). It is based on the phonics method whereby children are taught to connect graphemes with their corresponding 
TRUST IN PRINT 6

phonemes in isolation and to blend the sounds together to read regular and common irregular words. Children are also required to practise reading on a regular basis both at school and as part of their homework and are taught comprehension skills. By contrast, in Norway, children start school (first grade) the calendar year that they turn 6 and only then are they exposed to formal letter and reading instruction in a manner highly equivalent to the instruction provided in the UK Reception class. Before that, children aged 3 to 5 are typically in the same mixedage, preschool classrooms. The Norwegian framework plan for preschools (Rammeplan for barnehagens innhold og oppgaver, 2006) emphasizes "Communication, language and text" as one broad learning area out of several important learning areas. Within this content area, it is expected that children will be exposed to the sounds and rhythm of language. However, systematic reading instruction is not offered in preschool (see also Kurvers \& Uri, 2006). We would therefore expect the bias toward printed information to be delayed until 6 years if the age at which children are exposed to formal reading instruction is an important factor.

Second, the Norwegian context also provides us with an opportunity to look at the effect of simple decoding ability without the normally correlated factor of formal reading instruction. Some Norwegian children acquire the ability to decode before they enter the formal school setting. Children may learn letters informally (through television shows, games, i-pads and book-reading with their parents and preschool teachers) but their learning is not driven by an explicit message from adults (e.g., "Now we are going to learn the letter A") as it is in school. This allows us to isolate the effects of decoding ability that is not supported by formal reading instruction in a way that is not possible in a UK sample (where very few children display any decoding ability in advance of formal reading instruction). We were interested in finding out whether Norwegian 5-year-old preschoolers who have basic decoding ability but have not yet received any formal reading instruction would show a bias toward print over oral sources or whether this type of response would only be seen among 6- 
year-olds who had received systematic reading instruction - comparable to the 4-5-year-olds in the UK sample. To measure decoding ability, we adopted the word-picture matching task used by Robinson et al. (2013). This task was developed to differentiate beginning readers (children who are able to blend letter-sounds into words) from pre-readers who are unable to engage in such blending. Note that this task was not designed to assess individual differences in reading fluency.

All children were tested at the end of the school year to maximise the amount of formal literacy instruction experienced by that subset of children who were attending their first year of schooling. Whereas the original UK study was conducted with children in the age range 3 to 6 , we selected children in the age range 4 to 6 because we had no reason to expect that Norwegian 3-year-olds would perform differently from British 3-year-olds. In addition, we expected there to be a relatively large variation in reading skills within the group of children who were in their final year of preschool. Hence, to maximize such variation, we included a larger sample of 5-year-olds compared to the UK sample to explore this variation.

\section{Method}

Ethics statement. This research was approved by the Ethics committee of the Norwegian Centre for Research Data.

\section{Participants}

Participants were 96 predominantly Caucasian children with parental consent from 8 different preschool or school classrooms located in middle class areas in a large city in Norway: 26 children (10 girls) in their next-to-last year in preschool $\left(M_{\text {age }}=4 ; 8\right.$, range $=4 ; 3$ to $5 ; 0), 44$ children (24 girls) attending their final year in preschool $\left(M_{\text {age }}=5 ; 9\right.$, range $=5 ; 5$ to $6 ; 3)$ and 26 children (16 girls) in their first year of formal schooling $\left(M_{\text {age }}=6 ; 9\right.$, range $=$ $6 ; 3$ to $7 ; 4)$. All children were fluent speakers of Norwegian although a few spoke an additional language at home (e.g., Polish or Russian). 
TRUST IN PRINT 8

\section{Materials and procedure}

Trust task. We employed the materials and procedure from an earlier study conducted in the UK (Robinson et al., 2013). The experiment was designed to provide children with conflicting claims by two doll informants about which of several animal pictures illustrated an unfamiliar target with a fictitious name (e.g., 'koba'). Only one of the dolls had access to printed names for the pictures on a paper strip (the print doll) and this informant referred to the appropriate printed name on the strip when identifying the target (e.g., "This word says [koba]"). The other doll had a similar paper strip with matching pictures but there were stars instead of names printed beneath each picture (the stars doll). This informant made standalone oral statements (e.g., "This is the [koba]"). Children were asked to decide which doll was right. The stimuli consisted of three laminated sheets of paper, each bearing six coloured pictures of different animals. One picture sheet was used for the warm-up and two different sheets were used for the two test trials. Each of the test sheets displayed one familiar animal (a swan or a crab) and five unfamiliar animals, one of which was the target. No names for the animal pictures were provided on the test sheets. Each sheet was accompanied by a pair of matching laminated strips with thumbnails of the same animal pictures. The 'print strip' had the animal names in 9-point font size beneath each of the pictures, and the 'star strip' had a row of asterisks beneath each of the pictures in the same positions and font size. Because the non-words (e.g., 'koba') used in the English version of the print strip could also function as Norwegian non-words, we were able to use the same non-words in the Norwegian version of the task. For layout of the materials during the test trials see Figure 1.

Insert Figure 1 about here 
Children were first given a warm-up to familiarise them with the picture sheets and the fact that the strips had pictures matching those illustrated in the picture sheets. The experimenter (E) explicitly drew the child's attention to the fact that one strip had stars beneath each of the pictures while the other strip had printed names, saying: "This strip has stars underneath the pictures and this one has the names of the pictures underneath; see this one here says ladybird” ("Denne remsen har stjerner under bildene og denne har navnet på bildet under; se her står det marihøne"). To ensure children understood the relationship between the strips and the main sheet on subsequent test trials, they were asked to match a picture of a familiar animal on each strip with the same picture on the main sheet.

Two test trials followed. In test trial 1 , one of the picture sheets was placed in front of the child. Then two similar wooden dolls, dressed in red and blue clothes, respectively were introduced. E explained that she was giving one doll a strip with the names of the pictures on it and the other doll the strip with stars. It was emphasized that each doll had the same pictures on their strip as the child had on the sheet in front of them. Both strips were then placed close to E, positioned upside down to the child, so that children could see that there were names or stars on the strip but could not read the names. Each doll was placed next to its allocated strip. Next, children were asked to point to a familiar item on the sheet. Children were then told that the dolls were going to help them find an unfamiliar target, the koba ("kobaen" in Norwegian). E explained that one of the dolls would leave the table for a bit while the first doll would help them find the koba. The first doll looked at its strip and laid a small pointer toward one of the pictures (the platypus) and said either: "That's a koba" ("Der er kobaen") if the doll had the star strip or: "That word says koba" ("Der står det kobaen") if the doll had the print strip. The first doll then left the table, leaving behind its strip with the pointer in place. The second doll returned, selected a different item for the target (the elephant mouse), named it, and laid a pointer toward it. 
E then sat the two dolls next to their strips with the pointers indicating different pictures. After confirming that the dolls had made different claims, E asked children to decide which doll they thought was right: "So the two dolls said different animals didn't they (indicating picture strips with pointers)? Which doll do you think is right? ("Så de to dukkene sa ulike dyr ikke sant? Hvilken dukke tror du har rett?") ${ }^{1}$ A second test trial followed with the remaining stimulus sheet and two strips with animal pictures. In this trial, the task was to identify the neri ("nerien"). Across the two trials, each doll had a turn with the print strip. The order in which the red and blue dolls responded and the order in which the star strip or the print strip were presented was counterbalanced between children. Each child gained a print doll endorsement score between 0 and 2 according to the number of times they judged the doll with the print strip to be correct.

Word-picture matching task. Immediately following the trust task, basic decoding skills were assessed with a translated version of the word-picture matching task (Robinson et al, 2013). This consisted of one demonstration trial with a picture of a book and two separate label cards, bok (book) and tre (tree). E read the two labels out loud and demonstrated to the child how the book label could be matched with the book picture: "Here is a picture of a book, and here are two words, this one says 'book' and this one says 'tree' so I'm going to put the word that says book underneath the picture of the book because they match, do you see? They're a pair." Three test trials followed. On each trial, there were two pictures of familiar items (e.g., fish, bed) and four label cards to choose from (two matching the pictures and two fillers, (e.g., ball, apple). Across all trials, one of the fillers had the same beginning letter as one of the correct words. Therefore, children could not rely solely on the first sound of a word to make a decision. (See Appendix for a list of the pictures and label options used on the three trials.) We used the stimulus pictures from the UK version. To a large extent, we were also able to employ the Norwegian equivalents to the words used in the UK version, 
matching the difficulty level of the original task in terms of beginning letters and length of the words. For example, the target words "fish" and "socks" in English were translated into "fisk" and "sokker" in Norwegian. Moreover, the filler word "apple" in English was translated into "eple" in Norwegian (based on the assumption that the letters "a" and "e" are similar in terms of difficulty level). In two instances, we had to change the filler words to match the beginning letter of the Norwegian translation of the target words: e.g., in test trial 3, the translation of the target word "car" was "bil" in Norwegian. Therefore, we replaced the English filler word "cake" with the Norwegian filler word "brød" (bread in English) to match the beginning letter " $b$ " of the target word.

In each trial, the two pictures (named by E) and the four word cards (presented silently in random order) were laid out in front of the child and the child was asked to select the correct word card for each picture in turn. Participants could obtain a score of 0-2 per test trial according to the number of pictures they matched up with a correct label. They received a total score out of 6 for the entire task. It is worth noting that a low score is not necessarily an indicator of better reading than a score of 0 given that participants could guess the answers, unlike standard tests of word reading in which the probability of guessing correctly is very low. Accordingly, a score of 5 or 6 was taken as a pass at word-matching as in Robinson et al. (2013). This cut-off allowed us to exclude children who might have picked the correct words by chance. We ran a Monte-Carlo simulation of the task to model random responding (10000 repetitions) that confirmed this criterion exceeds chance level $(\alpha=.01)$.

\section{Results}

We first describe children's performance on the word-picture matching task. We then ask if children's selection of the print doll increased with age. Finally, we assess the relation between children's word matching performance and their selection of the print doll. We chose to run nonparametric analyses given that the data did not fully conform to the 
TRUST IN PRINT 12

assumptions required for parametric analyses. However, it is important to note that all results were replicated when parametric analyses were run.

Word-picture matching task: Children's mean word-picture matching scores in each age group are presented in Table 1. None of the 4-year-olds passed the word-picture matching task. Among the 5-year-olds, 20 out of 44 children passed the word-picture matching task (45\%), suggesting that many had gained some basic decoding skill without receiving formal instruction. Finally, all the 6-year-olds in the Norwegian sample passed the word-picture matching task. Note that in the UK sample (Robinson et al., 2013), 24\% of the 4-year-olds and $89 \%$ of the 5 -year-olds passed the same reading task. Thus, as expected, fewer 4- and 5-year-old Norwegian children passed the word-picture matching task as compared to UK children.

Trust task: Table 1 presents the mean print doll endorsement scores (choice of doll with print strip) across age groups. A Kruskal-Wallis one way ANOVA comparing across the three age groups $(4,5,6$ years $)$ confirmed a significant effect of age on print doll endorsement score, $H(2)=12.99, p=.002$. Follow-up pairwise comparisons with adjusted $p$ values showed that 4- and 5- year-olds (preschoolers) did not differ from each other ( $p=$ $1.00, r=.07$ ) but 6 -year-olds (first graders) trusted print significantly more than the 4-yearolds $(p=.003, r=.46)$ and 5-year-olds $(p=.006, r=.37)$. One-sample comparisons to chance (score of 1 ) indicated that 4- and 5-year-olds performed no differently from chance, $z$ $=-.73, p=.47$, and $z=.00, p=1.00$, respectively, whereas 6-year-olds demonstrated greater trust in the doll that referred to the printed labels, $z=3.55, p<.001, r=.70$ (Wilcoxon signed ranks tests).

There was also a main effect of presentation order, $U=784.0$, $z=-2.89, p=.004, r=.30$ (Mann-Whitney Test) indicating a tendency for children to place greater trust in the doll who made the first suggestion and therefore children who received the 
print-based testimony first $(M=1.40, S D=0.76)$ were more likely to trust the print doll than children who received the oral testimony first $(M=0.87, S D=0.91)$. This order bias was also found in the UK study and, as Robinson et al. (2013) note, does not undermine the basic finding of an increase with age in print-based trust given that presentation order was counterbalanced in each age group. Indeed, a check confirmed that there was no effect of presentation order on levels of trust in print among 6-year-olds $(p=.82)$; they trusted the print-based suggestions more often than would be expected by chance regardless of whether these were heard first, $M=1.71, S D=0.61, z=2.88, p=.004, r=.77$ or second, $M=1.58$, $S D=0.79, z=2.11, p=.035, r=.61$.

Insert Table 1 about here

When looking at the role of reading ability in the whole sample, there was a significant correlation between word-picture matching score and preferential trust in print, $r_{s}$ $(94)=.29, p=.004$. Children who failed the word-picture matching task $(n=50)$ performed no differently from chance on the print doll endorsement score; $M=0.86, S D=0.86, z=$ $1.15, p=.25$, whereas children who passed the word-picture matching task $(n=46)$ performed above chance: $M=1.46, S D=0.78, z=3.45, p=.001, r=.51$. That is, pre-readers with no measureable decoding ability showed no significant preference between the two dolls, whereas early readers with some basic decoding ability showed greater preference for the print doll.

Finally, to assess the impact of decoding ability in the absence of any experience of formal reading instruction, a separate analysis was conducted with the 5-year-olds $(N=44)$. Among this group, there was no correlation between word matching score and preferential trust, $r_{s}(42)=.11, p=.48$. Five-year-olds who passed the word-picture matching task $(n=20$, 
$\left.M_{\text {age }}=5 ; 9\right)$ did not obtain print doll endorsement scores significantly above chance, $M=$ $1.20, S D=0.83, z=1.07, p=.29$. Given the presentation order effect noted earlier we confirmed this finding of chance performance obtained for participants in both presentation order groups $(p s>.15)$ and the difference between these groups was not significant $(p=.32$, for descriptives see below). Moreover, the print doll endorsement score of passers was not significantly different from the group of 5-year-olds who failed the word-picture matching task $\left(n=24, M_{\text {age }}=5 ; 9\right), M=0.83, S D=0.92, U=294.0, z=1.36, p=.17, r=.21$ (see Table 2). We confirmed that this non-significant difference between word-picture matching groups applied regardless of whether children received the print testimony first (passers $M=$ $1.40, S D=0.84, n=10$ vs. failers $M=1.17, S D=0.94, n=12, U=68.0, z=.59, p=.63, r$ $=.12$ ) or second (passers $M=1.00, S D=0.82, n=10$ vs. failers $M=0.50, S D=0.80, n=12$, $U=81.0, z=1.51, p=.18, r=.32)$, although we note that the sample sizes become small when the data are broken down in this way.

Insert Table 2 about here

\section{Discussion}

Converging evidence shows that children with some basic decoding ability - but not pre-readers with no such ability - view the printed word as a particularly authoritative source of information as compared with oral testimony. This finding has led to the suggestion that learning to decode print is a key factor in young children's trust in text (e.g., Corriveau et al., 2014; Einav et al., 2013; Eyden et al., 2013; Robinson et al., 2013). As a strong test of this proposal, we replicated the experimental paradigm used in the UK by Robinson et al. (2013) in Norway, where children typically begin to receive formal school-based reading instruction 
considerably later, i.e., at about 6 years of age (compared to $4-5$ years in the UK). We reasoned that if decoding is a critical component of trust in print, then the emergence of this type of selective trust ought to be delayed in this population. This is indeed what we found: children showed selective trust in print only at 6 years of age, compared to $4-5$ years in the UK. In line with previous findings, children's word-picture matching ability correlated with their print endorsement score.

We also obtained an unexpected finding. Five-year-old preschoolers who had a basic decoding ability, as shown by their passing of our simple word-picture matching task, but had not yet been exposed to formal school-based reading instruction did not show selective trust in print and were no more trusting of this medium than their pre-reading peers. These findings suggest that basic decoding ability may not be a sufficient condition for trust in written sources; the experience of formal school-based reading instruction - which none of the 5-year-olds had had - appears to be necessary as well. However, caution is needed in interpreting these results given the relatively small number of 5-year-olds tested. We acknowledge that we cannot yet draw strong conclusions from these data regarding the critical importance of formal instruction given that an effect of informal reading instruction received outside of school may not have been detected with the present sample size. It will be important to replicate this finding with a larger sample size in future work.

Nevertheless, it is appropriate to consider why exposure to formal reading instruction in school might encourage children to treat print as a reliable source of information. One possibility is that when children learn to read in school, as opposed to at home, print is regularly associated with some kind of expertise or authority. First, the teacher repeatedly places explicit and intense focus on print in a way children are unlikely to have experienced previously. Admittedly, before formal instruction begins, children participate in literacyrelated activities at home such as being read to by their parents or talking about letters of the 
TRUST IN PRINT 16

alphabet (Treiman, Schmidt, Decker, Robins, Levine \& Demir, 2015). However, there is evidence to suggest that shared book reading during the preschool years is not a particularly print-focused activity for either adult or child. For example, the frequency with which parents explicitly refer to print during shared book reading with preschoolers (e.g., through comments, requests, and questions about print) was found to be low in a number of studies (Hammett, Kleek \& Huberty, 2003; Justice \& Ezell, 2000; Lynch, Anderson, Anderson, \& Shapiro, 2008; Sonnenschein \& Munsterman, 2002; for review see, Evans \& Saint-Aubin, 2010). Converging evidence from eye-tracking studies shows that 4-5 year-old preschoolers with very basic literacy knowledge rarely attend to print (between 2-7\% fixations) when listening to their parents read illustrated storybooks (Evans \& Saint-Aubin, 2005; Justice, Skibbe, Canning, \& Lankford, 2005; Roy-Charland, Saint-Aubin, \& Evans, 2007) or even while themselves 'reading' an alphabet book, where print is particularly salient (Evans, SaintAubin, \& Landry, 2009). Instead, the focus by both parent and child tends to centre on the illustrations or story content. It may be that the shift from implicit exposure to print at home to directed and explicit focus on print during literacy instruction encourages an increase in the amount of attention the child spontaneously gives to this medium, especially once they begin to decode words for themselves.

Second, in teaching children to read, the teacher often presents the word to be read together with its pictorial counterpart and draws attention to the parallels between them. This may serve to raise children's awareness of how written information directly maps onto a reality of both familiar and unfamiliar referents and to reinforce the impression of print as a veridical source of information. Indeed, given that children's reading at this stage will typically be restricted to single words that correctly correspond to real and identifiable referents, it is possible that they will initially make the default assumption that print is accurate because they do not yet appreciate when and why it could be inaccurate. In contrast, 
inaccuracies (e.g., mistakes, lies or jokes) are likely to be much more common in speech that children are exposed to every day and this may contribute to their relatively greater scepticism toward this medium. There is a wealth of evidence showing that children are sensitive to such inaccuracies in oral testimony from an early age (Koenig \& Harris, 2005; for reviews see, Harris, 2012; Harris et al., 2018; Mills, 2013).

Finally, teachers may foster deference toward print by emphasizing literacy as an achievement. In contrast, children who acquire basic reading skills informally, based on more implicit exposure to print in their environment, may lack this type of reinforcement.

A fascinating question for future research is whether other activities that are introduced and endorsed by a teacher on a regular basis would similarly acquire authority, beyond that attained by more informal home-based learning, and how this would interact with the child's own ability to extract meaning from such entities. For example, would children place greater trust in written numerals over oral claims about the solution to an arithmetic problem? Would such trust emerge only when children can decode the numeric notations themselves, and have received formal numeracy instruction at school?

In conclusion, our results in Norway reinforce the claim that children who have received literacy instruction and acquired a basic decoding ability invest more trust in written as compared to oral information. Consistent with the slower timetable for literacy instruction in Norway, 6-year-olds but not 4- and 5-year-olds displayed this bias toward written information. Indeed, 5-year-olds with a basic decoding ability but no exposure to formal literacy instruction did not show the bias. Future research should be able to determine the origin and scope of this type of selective trust. 


\section{References}

Corriveau, K. H., Einav, S., Robinson, E. J., \& Harris, P. L. (2014). To the letter: Early readers trust print-based over oral instructions to guide their actions. British Journal of Developmental Psychology, 32, 345-358. doi:10.1111/bjdp.12046

Einav, S., Robinson, E. J., \& Fox, A. (2013). Take it as read: Origins of trust in knowledge gained from print. Journal of Experimental Child Psychology, 114, 262-274. doi:10.1016/j.jecp.2012.09.016

Evans, M. A., \& Saint-Aubin, J. (2005). What children are looking at during shared storybook reading: Evidence from eye movement monitoring. Psychological Science, 16, 913-920. doi:10.1111/j.1467-9280.2005.01636.x

Evans, M. A., \& Saint-Aubin, J. (2010). An Eye for Print: Child and adult attention to print during shared book reading. In D. Aram \& O. Korat (Eds.), Literacy Development and Enhancement Across Orthographies and Cultures (pp. 43-53). New York: Springer. doi:10.1007/978-1-4419-0834-6

Evans, M. A., Saint-Aubin, J., \& Landry, N. (2009). Letter names and alphabet book reading by senior kindergarteners: An eye movement study. Child Development, 80, 1824-1841. doi:10.1111/j.1467-8624.2009.01370.x

Eyden, J., Robinson, E. J., \& Einav, S. (2014). Children's trust in unexpected oral versus printed suggestions: Limitations of the power of print. British Journal of Developmental Psychology, 32, 430-439. doi:10.1111/bjdp.12054

Eyden, J., Robinson, E. J., Einav, S., \& Jaswal, V. K. (2013). The power of print: Children's trust in unexpected printed suggestions. Journal of Experimental Child Psychology, 116, 593-608. doi:10.1016/j.jecp.2013.06.012

Hammett, L. A., van Kleeck, A., \& Huberty, C. J. (2003). Patterns of parents' extratextual 
interactions during book sharing with preschool children: A cluster analysis study. Reading Research Quarterly, 38, 442-467.

Harris, P. L. (2012). Trusting what you're told: How children learn from others. Cambridge, Mass.: Harvard University Press.

Harris, P. L., Koenig, M. A., Corriveau, K. H., \& Jaswal, V. K. (2018). Cognitive foundations of learning from testimony. Annual Review of Psychology, 69, 251-73.

Hatcher, P. J., Hulme, C., \& Ellis, A. W. (1994). Ameliorating early reading failure by integrating the teaching of reading and phonological skills: The phonological linkage hypothesis. Child Development, 65, 41-57. doi:10.1111/j.1467-8624.1994.tb00733.x

Justice, L. M., \& Ezell, H. K. (2000). Enhancing children's print and word awareness through home-based parent intervention. American Journal of Speech-Language Pathology, 9 , 257-269. doi:10.1044/1058-0360.0903.257

Justice, L. M., Skibbe, L. E., Canning, A., \& Lankford, C. (2005). Pre-schoolers, print and storybooks: an observational study using eye movement analysis. Journal of Research in Reading, 28, 229-243.

Koenig, M. A., \& Harris, P. L. (2005). Preschoolers mistrust ignorant and inaccurate speakers. Child Development, 76, 1261-1277. doi:10.1111/j.1467-8624.2005.00849.x

Kurvers, J., \& Uri, H. (2006). Metalexical awareness: Development, methodology or written language? A cross-linguistic comparison. Journal of Psycholinguistic Research, 35, 353-367. doi:10.1007/s10936-006-9019-6

Lynch, J., Anderson, J., Anderson, A., \& Shapiro, J. (2008). Parents and preschool children Interacting with storybooks: Children's early literacy achievement. Reading Horizons, $48,227-242$.

Mills, C. M. (2013). Knowing when to doubt: Developing a critical stance when learning 
TRUST IN PRINT 20

from others. Developmental Psychology, 49, 404-418. doi:10.1037/a0029500

Robinson, E. J., \& Einav, S. (2014). Trust and skepticism: Children's selective learning from testimony. London: Psychology Press. doi:10.4324/9781315849362

Robinson, E. J., Einav, S., \& Fox, A. (2013). Reading to learn: prereaders' and early readers' trust in text as a source of knowledge. Developmental Psychology, 49, 505-513. doi:10.1037/a0029494

Roy-Charland, A., Saint-Aubin, J., \& Evans, M. A. (2007). Eye movements in shared book reading with children from kindergarten to Grade 4. Reading and Writing, 20, 909-931. doi:10.1007/s11145-007-9059-9

Sonnenschein, S., \& Munsterman, K. (2002). The influence of home-based reading interactions on 5-year-olds' reading motivations and early literacy development. Early Childhood Research Quarterly, 17, 318-337. doi:10.1016/S0885-2006(02)00167-9

Treiman, R., Schmidt, J., Decker, K., Robins, S., Levine, S. C., \& Demir, Ö. E. (2015). Parents' talk about letters with their young children. Child Development, 86, 1406-1418. doi:10.1111/cdev.12385

The Norwegian Ministry of Education and Research (2006). Framework Plan for the Content and Tasks of Kindergartens. Retrieved from https://www.regjeringen.no/globalassets/upload/kilde/kd/reg/2006/0001/ddd/pdfv/28202 3-rammeplanen.pdf

UK Department for Education (2012). Statutory Framework for the Early Years Foundation Stage: Setting the standards for learning, development and care for children from birth to five (Reference: DFE-00023-2012). Retrieved from https://www.education.gov.uk/publications/standard/AllPublications/Page1/DFE-000232012 


\section{Footnote}

${ }^{1}$ In addition, to find out whether children who placed trust in the print doll could generalize this decision to a new context with no print present, participants were asked to point to the target on the picture sheet, as in Robinson et al. (2013): "Can you find the neri on your sheet?" Children who selected the doll with the names strip as correct and also generalized to the correct target on the test sheet received a point to obtain a 'strict criterion' score of 1 in each of the two test trials. We found that children who chose the print doll to be correct would afterwards typically endorse the print doll's choice when identifying the koba or the neri on the sheet in front of them: 103 out of 110 trials (94\%). Preliminary analyses confirmed that the main results were highly similar irrespective of which doll endorsement score we used as a dependent variable. To allow comparisons with chance (see Robinson et al. 2013), we present the analyses conducted with the less strict print doll endorsement score as the dependent variable. 
TRUST IN PRINT 22

Table 1

Mean (SD) frequency of endorsement of the print doll and word-picture matching scores for children in each age group

\begin{tabular}{lcc}
\hline & $\begin{array}{c}\text { Print doll } \\
\text { endorsement }\end{array}$ & $\begin{array}{c}\text { Word-picture } \\
\text { score }\end{array}$ \\
& matching score \\
& $(\max =6)$ & \\
Age group & & \\
\hline Next to last year in & $0.88(0.82)$ & $1.85(1.08)$ \\
preschool: & \\
4 years 8 months & \\
$(n=26)$ & \\
Last year in preschool: & $1.00(0.89)$ & $3.89(1.88)$ \\
5 years 9 months & \\
$(n=44)$ & \\
First grade: & \\
6 years 9 months & \\
$(n=26)$ & \\
\hline
\end{tabular}




\section{TRUST IN PRINT 23}

Table 2

Mean frequency of endorsement of the print doll (maximum =2) as a function of age and reading status

\begin{tabular}{|c|c|c|c|c|c|c|c|c|}
\hline & \multicolumn{4}{|c|}{ Basic Decoding } & \multicolumn{4}{|c|}{ No Basic decoding } \\
\hline Age group & $\mathrm{n}$ & Mean (SD) & $\mathrm{Z}$ & $\mathrm{r}$ & $\mathrm{n}$ & Mean (SD) & $\mathrm{Z}$ & $\mathrm{r}$ \\
\hline 4 years & 0 & & & & 26 & $0.88(0.82)$ & -.73 & .14 \\
\hline 5 years & 20 & $1.20(0.83)$ & 1.07 & .24 & 24 & $0.83(0.92)$ & -.89 & .18 \\
\hline 6 years & 26 & $1.65(0.69)$ & $3.55^{*}$ & .70 & 0 & & & \\
\hline
\end{tabular}




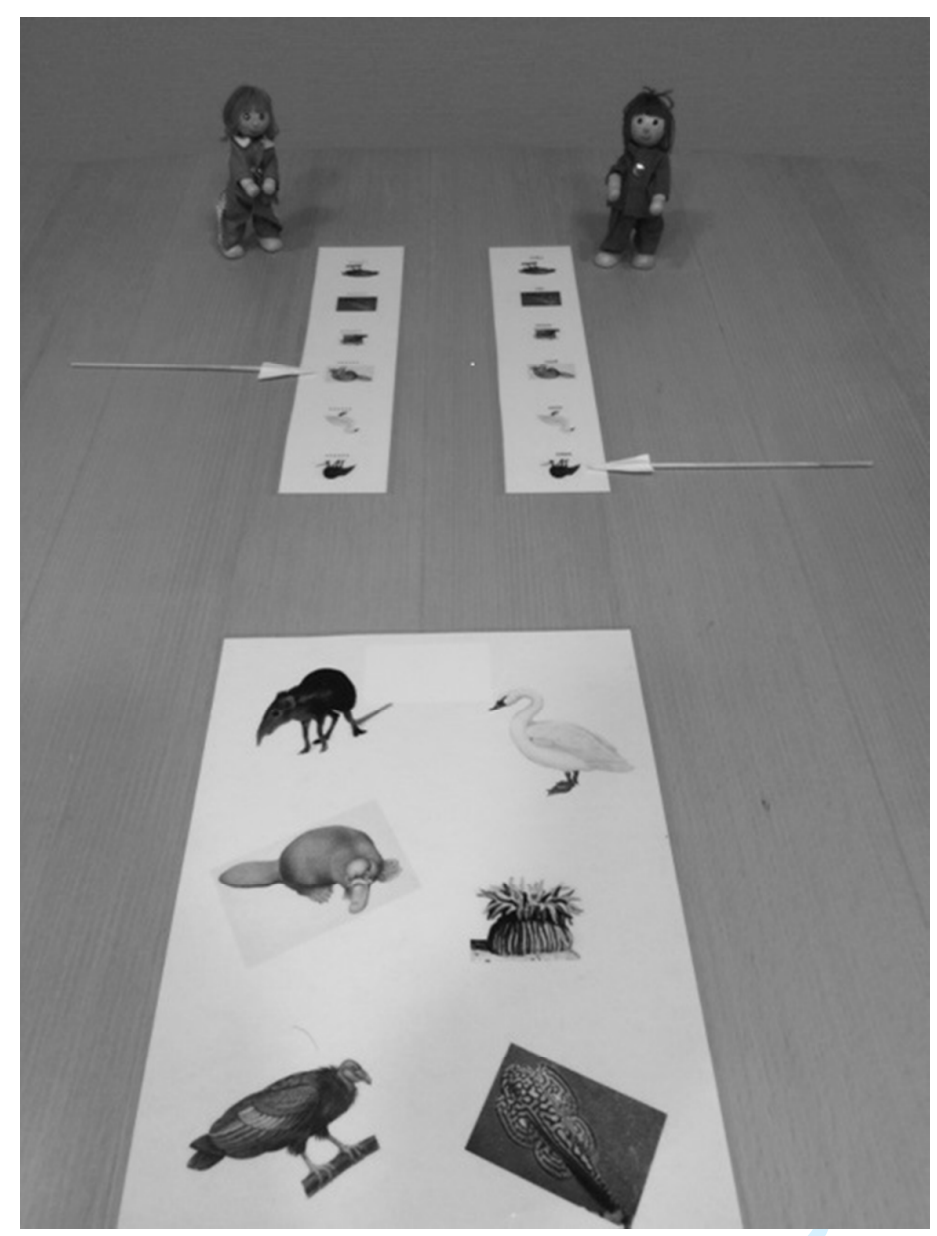

Figure 1. Layout of the stimuli in the trust task from the participant's perspective. 
TRUST IN PRINT 25

Appendix: Pictures and labels used in the word-picture matching task

\begin{tabular}{|c|c|c|}
\hline Test trial & Pictures & Label choices in English / Norwegian \\
\hline \multirow[t]{4}{*}{1} & Flowers & Flowers/Blomster \\
\hline & Shoes & Shoes/Sko \\
\hline & & Sheep/Sau \\
\hline & & Hat/Hatt \\
\hline \multirow[t]{4}{*}{2} & Fish & Fish/Fisk \\
\hline & Bed & Bed/Seng \\
\hline & & Ball/Sofa \\
\hline & & Apple/Eple \\
\hline \multirow[t]{3}{*}{3} & Car & Car/Bil \\
\hline & Socks & Socks/Sokker \\
\hline & & $\begin{array}{l}\text { Bread/Brød } \\
\text { Train/Tog }\end{array}$ \\
\hline
\end{tabular}

